\title{
УСТАВ 0 ЦЕНЗУРЕ 1826 ГОДА В КОНТЕКСТЕ ВНУТРЕННЕЙ ПОЛИТИКИ НАЧАЛ ЦАРСТВОВАНИЯ НИКОЛАЯ І
}

\section{THE STATUTE OF CENSORSHIP OF 1826 IN THE CONTEXT OF DOMESTIC POLITICS BEGAN THE REIGN OF NICHOLAS I}

\section{Lebedyantsev}

Summary:This is an article about specific features of the Law on Censorship 1826. After the publishing, it was called «lron» and it was criticized both by liberals and conservative persons. The article researches the main features of «lron» Law and compares it with Law on Censorship 1804 of Alexander I and Law on Censorship 1828. The development of this field of law is seen in the context of the character of Nicolas I and some events connected with the beginning of his ruling what is the novelty of the article. In a result, it is becoming clear that the government of Nicolas I observed public mood and the tsar, despite his reputation of a terrible ruler, could give up and make his policy softer.

Keywords: Nicolas I, liberalism, conservatism, the Law on Censorship, fields of law, Alexander I.

\author{
Лебедянцев Иван Михайлович \\ Преподаватель, ЧОУРО «НЕРПЦ(МП) «Православная \\ гимназия имени Серафима Саровского г. Дзержинска» \\ leb1000.mm@yandex.ru
}

Аннотация: В данной статье исследуются специфические черты Устава 0 цензуре 1826 года. После выхода Устава, прозванного в народе «Уугунным», последовал всплеск общественного негодования. Критика закона о цензуре последовала не только из среды либеральной общественности, но и от консерваторов. В статье наряду с основными положениями Устава 1826 года освещаются особенности цензурных уставов 1804 и 1828 гг. Развитие цензурного законодательства рассматривается в контексте личностных особенностей и условий восшествия на престол Николая I, что является научной новизной публикации. В результате исследования делается вывод 0 том, что, несмотря на жесткие охранительные мероприятия, Николай I чутко относился к общественному мнению и под давлением общественности шел на смягчение своих внутриполитических мер.

Ключевые слова: Николай I, либерализм, консерватизм, цензурное законодательство, отрасли права, Александр I.

классиков отечественной историографии и литературоведения $[4,6]$, а также работы современных ученых $[1,3,5,9,11,12,18]$.

Практическая значимость исследования состоит в возможности использования его результатов для образовательного процесса. Выводы статьи могут быть использованы для курсов истории журналистики и правовой мысли в России. Кроме того, результаты исследования могут быть полезны для осмысления взаимоотношений власти и общества в современном мире.

Николай I является одной из самых противоречивых фигур русской истории. С одной стороны, его эпоха период наивысшего внешнеполитического могущества России, расцвет культуры, время появления самых значительных произведений русской литературы; с другой - это пора цензурных ограничений и полицейского контроля. Такой же противоречивой, под стать эпохе, была и личность государя. Образ царя сильно разнится в воспоминаниях современников [11]. Одни видят его ограниченным, грубым и недалеким тираном, другие отмечают трудолюбие, самоотдачу и преданность долгу. Также и в современной историографии взгляды на его правление часто бывают диаметрально противоположными [9].

На внутреннюю политику Николая I наибольшее вли- 
яние оказали два момента: воспитание будущего царя и обстоятельства, при которых произошло его восшествие на трон.

Будучи только третьим сыном Павла I, Николай никем не рассматривался как серьезный кандидат на престол. Российским самодержцем после Павла, согласно изданному им указу о престолонаследии 1797 года [2], становился его старший сын. То есть будущий император Александр І. За ним в случае отсутствия потомства следовал второй сын Павла Константин. Только в том случае, если бы Александр и Константин не оставили прямых наследников по мужской линии, власть перешла бы к Николаю. Но подобная ситуация тогда представлялась более чем гипотетической. Сам Николай I узнал о том, что станет монархов лишь за несколько лет до смерти своего брата [3].

Другим фактором, определившим характер нового правления, стали события декабря 1825. После демарша на Сенатской площади Николай навсегда оставил мысли о либеральных преобразованиях.

Таким образом, годы царствования Николая в силу условий, определивших его развитие, необходимо должны были отличаться от времени правления его старшего брата, нацеленного на реформы, приведение в порядок российской экономики и социальной системы.

Положение, которое занимал Николай при дворе своего отца, а потом брата, сыграло решающую роль в развитии его личности и определило характер царствования. В.О. Ключевский прекрасно отмечает разницу между характером Николая и его брата-преобразователя. «Александр смотрел на Россию сверху, со своей философской политической высоты, а, как мы знаем, на известной высоте реальные очертания или неправильности жизни исчезают. Николай имел возможность взглянуть на существующее снизу, оттуда, откуда смотрят рабочие, не руководствуясь идеями, не строя планов» $[6$, с.264].

Одной из отличительных черт николаевской эпохи являлась обширная законотворческая деятельность правительствующих кругов. В начале тридцатых возвращенный из ссылки М.М. Сперанский издает Полное собрание законов Российской империи [8] - крупнейший свод нормативных актов, охватывающий период в сто восемьдесят лет. А потом и «Свод законов Российской империи» [10] - многотомное собрание действующих законов государства.

Другим важным событием этой эпохи стало появление в 1845 году «Уложения о наказаниях уголовных и исправительных» [14], также подготовленный Вторым отделением имперской канцелярии. Это был первый
Уголовный кодекс в истории России. Хотя собрание уголовных законов находилось уже в пятнадцатом томе «Свода законов Российской империи», но как отдельный кодекс появляется только в 1845 году. Важен здесь не только сам факт появления Уголовного кодекса, а процесс, частью которого он явился. Собственно, появление законодательства в сфере уголовных преступлений свидетельствует о начале дифференциации отраслей права в российской юриспруденции.

Новое правительство не могло обойти стороной и вопроса о цензурном законодательстве. В 1826 году, вскоре после восшествия Николая I на престол, появляется знаменитый «Чугунный» устав о цензуре [16], а в 1828 году новый, более либеральный законопроект [17].

Первый российский Устав о Цензуре появился еще в начале девятнадцатого столетия. Он был одним из плодов деятельности «Негласного комитета» - круга приближенных к молодому императору лиц. Александр I в начале своего царствования проводил либеральную политику. Это сказалось и на законодательстве эпохи. Так, уже в самом начале своего правления (1803 год) Александр издает знаменитый «Указ о вольных хлебопашцах» [7] - закон, позволявший помещикам отпускать своих крестьян на волю с наделом земли.

Устав 1804 года также был либеральным. Благодаря ему стало возможно появление в двадцатых годах журналов, таких как «Невский зритель», «Мнемозина» или «Полярная звезда», которые были проводниками декабристских идей [4, с.196].

Либеральным шагом был уже сам факт создания цензурного устава. Во многих своих статьях он даже защищает автора от произвола чиновников. Например, в п.21 читаем: «...Цензура в запрещении печатания или пропуска книг и сочинений, руководствуется благоразумным снисхождением, удаляясь всякого пристрастного толкования сочинений (курсив - И.Л.) или мест в оные, которые по каким-либо мнимым причинам кажутся подлежащими запрещению. Когда место, подверженное сомнению, имеет двоякий смысл, в таком случае лучше истолковать оное выгоднейшим для сочинителя образом, (курсив - И.Л.) нежели его преследовать» [15, с.89].

Другим важным моментом было положение периодической печати. В п. 23-24 указывается, что периодические издания не должны быть задерживаемы цензурными ведомствами, поскольку главное они «долженствуют выходить в срочное время и теряют цену новости, если издаются позже» [15, с.89].

Таким образом, Устав 1804 года не только не нарушал права сочинителей, но и защищал их от произвольного толкования их трудов чиновниками. Кроме того, он за- 
щищал периодические издания от бюрократических проволочек.

«В целом, в первую половину правления Александра I сильного давления на печать не было» [18, с.50]. Однако его политика изменилась после Заграничных походов и создания Священного союза. Во второй половине своего царствования Александр становится консерватором. Но, несмотря на это, Устав 1804 при Александре I так и не был заменен. Вопрос о новом, более строгом и полном цензурном уставе встал перед следующим русским монархом Николаем I.

В 1826 году увидел свет новый Устав о цензуре. «Среди общественности устав называли «чугунным», который тяжелым прессом придавил печать» [5, с.112]. Такое прозвание закрепилось за новым документом из-за его объемности, неказистости и непонятности. Он был в несколько раз пространнее Устава 1804 года и охватывал не только вопросы непосредственно цензурных ограничений, но и формирования общественного мнения, книгопечатания и др. «Этот Устав отражал максимально жесткий подход, принятый во властных структурах после восстания декабристов 1825 года. Устав пресекает всякое вольнодумство, запрещая любые публикации, содержащие даже предложения о каком-либо государственном переустройстве» [1, с.195].

«Чугунный» устав запрещал любые проявления критического взгляда на устройство общества, какие бы ни было социальные проблемы и даже на размышления о ходе исторического процесса. В 169 параграфе устава написано: «Запрещаются к печатанию всякие частных людей предположения о преобразовании каких-либо частей Государственного управления, или изменении прав и преимуществ. Высочайше дарованных разным состояниям и сословиям Государственным, если предположения сии не одобрены еще Правительством» [16, с.170-171].

Особое негодование в обществе вызвал параграф, посвященный историческим сочинениям, которые в тот момент были особенно популярны. В п.181 по этом поводу написано: «История не должна заключать в себе произвольных умствований, которые не принадлежат повествованию и коих содержание противно правилам сего устава» [16, с.173]. Согласно этому пункту к печати, не могли быть допущены произведения классиков античной историографии, никто из современных западных историков и даже лояльный к власти и обласканный императорами Карамзин. Собственно говоря, сам Николай І скептически отнесся к этому пункту, но уступая просьбам Шишкова, сохранил его без изменений [4, с.197-198].

Другой знаковой чертой Устава стало создание целой системы надзорных органов в сфере печати. В Уставе
1804 года не предусматривалось создание каких либо, специальных надзорных органов. Так, в четвертом параграфе читаем: «Для рассматривания книг и сочинений учреждаются Цензурные Комитеты при Университетах из Профессоров и Магистров и состоят под непосредственным ведением Университетов» [15, с.85-86]. Т.е. хотя цензура и цензурные ограничения, несомненно, существовали, размах их был столь невелик, что не требовал создания специальных органов и должностей. Цензурные органы создавались, но они существовали при университетах, и можно считать их небольшими подразделениями ВУЗов, а не отдельными бюрократическими органами. Отдельный Цензурный комитет был создан в Санкт-Петербурге, но это было, как написано в Уставе 1804 г., вынужденной необходимостью в связи с отсутствием в столице университета [15, с.83]. Законопроект 1826 года, напротив, предусматривал создание целой системы цензурных органов. Не случайно, что устройству цензурных комитетов, обязанностям цензоров и проч. посвящены целых три главы нового устава. Кроме того, что особенно важно, «устав определил должность цензора как самостоятельную профессию... Это ставило статус цензора в жесткие рамки: в случае проступка цензор отвечал за все сполна» [12, с.81].

Стало невозможно совмещать должность цензора с каким-либо другим постом. Должность Цензоров вообще, требующая постоянного внимания, и сама по себе многотрудная и важная, не может быть соединена, в одном лице, с другой должностью» [16, с.135]. Правда, «на должность цензоров правительство стало привлекать писателей и ученых, деятельность которых имела общественное значение. Этим оно старалось заручиться поддержкой общественности и повлиять на литературные круги» [5, с.112]. Но это был лишь небольшой популистский шаг, к которым николаевское правительство охотно прибегало. Можно найти много примеров таких популистских действий во взаимоотношениях власти и литераторов, которые в те годы направляли общественное мнение. Самым известным примером было возвращение из ссылки Пушкина, которого Николай I удостоил еще и личной аудиенции.

Другим примером, ярко иллюстрирующим взаимоотношения власти и литературной общественности, является история, связанная с изданием знаменитых «Записок охотника» Тургенева. За критику крепостничества автор подвергся опале и даже был отправлен в ссылку. При этом Николай I уволил без права на пенсию цензора, давшего разрешение на издание книги, но саму книгу не запретил. Император, по всей видимости, не подверг ее запрету «потому, что не захотел еще раз привлекать внимания к писателю, уже наказанному» [13, с.565]. Здесь в очередной раз сказалось внимание монарха к общественному мнению. 
Точно также царское правительство пошло на уступки общественности в случае с цензурным уставом. Устав 1826 года подвергся всесторонней критике. Еще до его утверждения и обнародования самые скандальные его положения стали известны столичной общественности. И в салонах, переписке, личных беседах новый закон обсуждался и критиковался. О недовольствах Уставом доносили царю. Кроме того, скандальный законопроект подвергся критике не только со стороны либеральных кругов, но и «справа», от представителей консервативных и охранительных тенденций российского общества. С всесторонней критикой Устава 1826 года выступил знаменитый С.С. Уваров, один из творцов «теории официальной народности», человек, который впоследствии станет символом цензуры и государственного контроля над образованием и культурой. В конце 1826 года им была создана записка с подробным разбором и критикой всех спорных моментов Устава [4, с.210].

Все это привело к тому, что император поддался давлению со стороны общества, и в том же 1826 году им был создан комитет для пересмотра цензурного устава. Результатом работы комитета было создание в 1828 году нового Устава о цензуре. В новом Уставе уже отсутствовали спорные статьи, позволявшие цензору толковать смысл произведений или запрещавшие историку делать выводы и обобщения. Кроме того, Устав 1828 года, наконец, решил важный вопрос об иностранных произведениях. Вторая часть этого Устава посвящена цензуре иностранных книг. В целом, новый закон о цензуре был более либеральным, продуманным и взвешенным. Этот Устав просуществовал вплоть до эпохи Великих реформ и был заменен лишь в 1865 году.

\section{Выво $\Delta ы$}

Таким образом, на примере событий 1826-1828 гг., когда шел процесс разработки нового цензурного законодательства, мы видим, что Николай I отнюдь не был несгибаемым правителем с железной волей, каким он часто представлялся современникам. Император, несмотря на усиление цензуры и полицейского контроля, очень чутко относился к изменениям в общественном мнении. Собственно, само усиление цезуры об этом свидетельствует. Цензурные ведомства создавались для того, чтобы направлять общественное мнение, а тотальная слежка тайной полиции имела своей целью не только выявление и искоренение крамолы, но и выяснение общественных настроений. И хотя Николай I часто шел на непопулярные меры, его отступление перед давлением различных социальных групп показывает, что он пытался следить за тем, какой уровень общественного недовольства эти меры вызывают. Император утвердил «Чугунный» устав 1826 года, несмотря на тот факт, что сам был недоволен некоторыми, наиболее ограничивающими свободу слова статьями, поскольку этот Устав соответствовал его политической программе. Но когда этот законопроект подвергся всесторонней критике как слева, так и справа, царь уступил общественному недовольству и вскоре утвердил новый, более либеральный устав.

\section{ЛИТЕРАТУРА}

1. Амиров В.М., Чудинов А.П. Российская журналистика под гнетом цензуры // Политическая лингвистика, 2010 - №2 (32), с.194-195.

2. Акт, Высочайше утверждённый в день священной Коронации Его Императорского Величества, и положенный для хранения на престол Успенского Собора // Полное собрание законов Российской империи. — СПб.: Типография II отделения Собственной Его Императорского Величества канцелярии, 1830. - T. XXIV. - C. 587-589.

3. Выскочков Л.М. До междуцарствия. «Ангел» Александр и Николай Павлович (3 июля 1819 - 1 сентября 1825) // Петербургский исторический журнал, 2019 - №2(22).

4. Гиллельсон М.И. Литературная политика царизма после 14 декабря 1825 г.// Пушкин: исследования и материалы/ АН СССР. Ин-т рус. лит. (Пушкин. Дом). - Л.: Наука. Ленинград. отд-ние, 1978. - Т.8. - С.195-218.

5. Горячева Е.М. Особенности административного и уголовного законодательства в сфере борьбы с инакомыслием в годы правления Николая I // Известия Тульского государственного университета. Экономические и юридические науки, 2014 - №3-2. С.111-119.

6. Ключевский В.0. Курс русской истории. Часть 5//Сочинения в 8 Т. Т.5. М.:1958.

7. 06 отпуске помещиком крестьян своих на волю по заключении условий на обоюдном согласии основанных // Полное Собрание Законов Российской Империи: Собрание первое: с 1649 по 12 декабря 1825 года. - СПб.: Тип. 2-го Отд-ния Его Собств. Е. И. В. Канцелярии, 1830. - в 48 т. Т.XXVII. С.462.

8. Полное Собрание Законов Российской Империи: Собрание первое: с 1649 по 12 декабря 1825 года. - СПб.: Тип. 2-го Отд-ния Его Собств. Е. И. В. Канцелярии, 1830. - в 48 т.

9. Поташев А.Ф. Историография царствования Николая I // Вестник Адыгейского государственного университета. Серия 1: Регионоведение: философия, история, социология, юриспруденция, политология, культурология, 2012 - №2.

10. Свод Законов Российской Империи. - СПб.: Тип. 2-го Отд-ния Его Собств. Е. И. В. Канцелярии, 1830. - в 15 т.

11. Рахматуллин М.А. Император Николай I глазами современников//0течественная история, 2004, №6.

12. Терещенко Я.В. Цензура и журналистика в период правления Николая I / Вестник РГГУ. Серия: Литературоведение. Языкознание. Культурология, 2008 - 


\section{№11. C.80-86.}

13. Тургенев И.С. Собрание сочинений в 6 Т. Т.1. М.:1968.

14. Уложение о наказаниях уголовных и исправительных. - Санкт-Петербург: Тип. 2 отд-ния собств. е. и. в. канцелярии, 1845.

15. Устав о цензуре 1804 г. // Сборник постановлений и распоряжений по цензуре с 1720 по 1862 год: напечатан по распоряжению Министерства народного просвещения. - Санкт-Петербург: в Тип. Морского министерства, 1862. С.81-87.

16. Устав о цензуре 1826 г. // Сборник постановлений и распоряжений по цензуре с 1720 по 1862 год: напечатан по распоряжению Министерства народного просвещения. - Санкт-Петербург в Тип. Морского министерства, 1862. С.125-197.

17. Устав о цензуре: [Утв. 22 апр. 1828 г.: с приложением Штатов и Положения о правах сочинителей]. - Санкт-Петербург: тип. Деп. нар. прос., 1829. - 101 с. 18. Чирскова И.М. «Тело власти»: цензура как феномен культуры // Международный журнал исследований культуры, 2015, №2 (19), с. 47-51.

с Лебедянцев Иван Михайлович (leb1000.mm@yandex.ru).

Журнал «Современная наука: актуальные проблемы теории и практики»

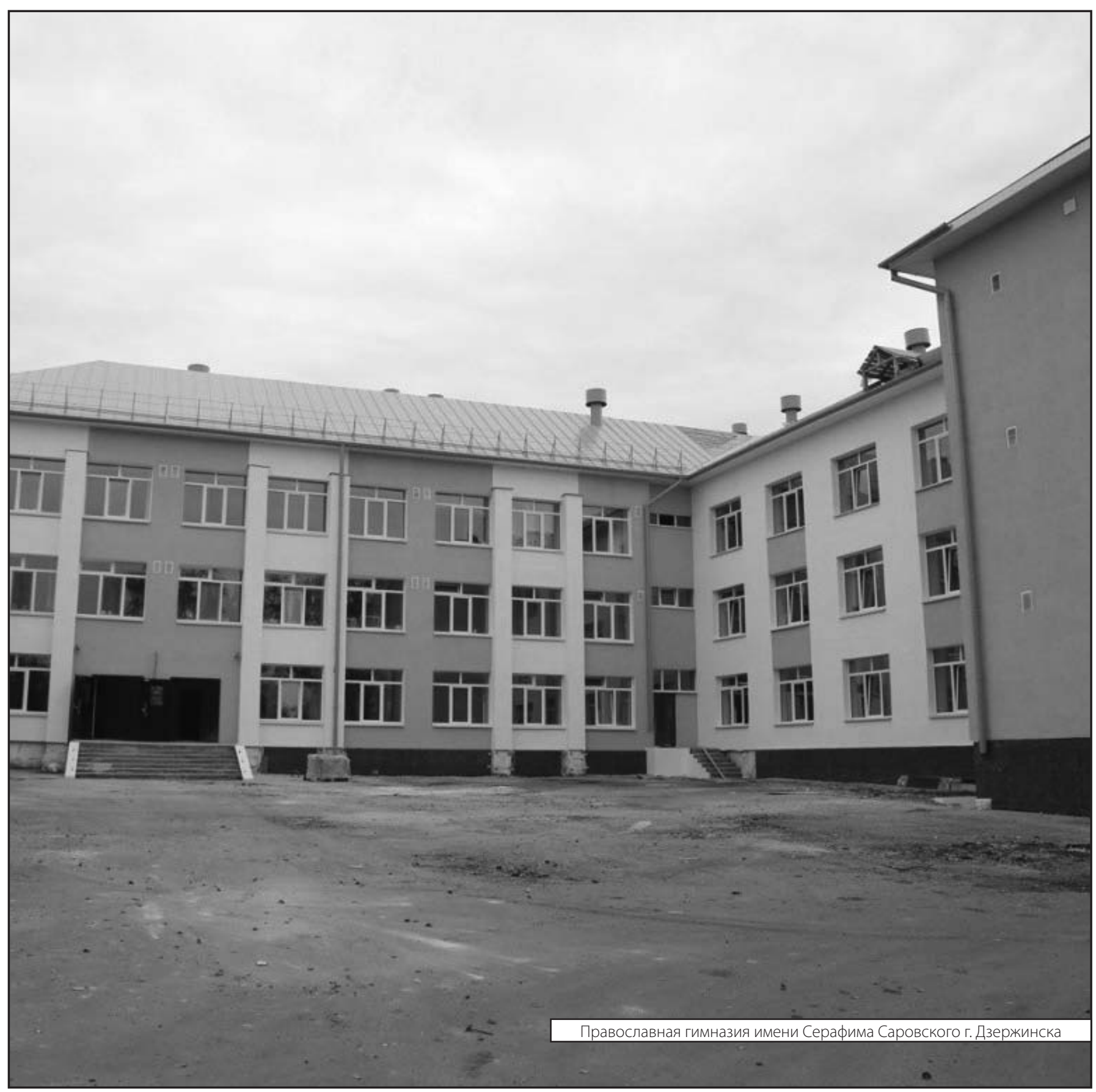

